that it is not used as commonly as its effectiveness dictates it should be. We studied referrals to our Cardiology Unit from our linked national psychiatric unit to characterise the cardiac status in these individuals and determine outcome.

Methods Retrospective review of all adult patients on clozapine referred to our cardiology unit over 9 years. Electrocardiograms and echocardiographic data was collected as was mortality data. Students t-test, Mann-Whitney $\mathrm{U}$ and linear regression were used to analyse results.

Results 29 patients were seen by cardiology in the outpatient setting, all had a diagnosis of schizophrenia. Mean age 43 \pm 12 years; $34 \%$ female ( $n=10$; table 1 ). 59 others underwent diagnostic testing but were never referred for review.

Median left ventricular ejection fraction (LVEF) was 52 (IQR44\%-55\%), median HR 98 (IQR85-114bpm). No significant difference in age at review and LVEF, QRS duration, heart rate or QTc interval. There was no significant relationship between duration on clozapine and LVEF $(p=0.77)$ at review. There was a significant difference in length of time on clozapine and QTc interval ( $\mathrm{p}=0.02 ; \mathrm{r}=0.46$; figure 1 ).

Follow-up time was 4.4 years(IQR 2-6) from initial review; 3 patients died (subarachnoid haemorrhage, aortic aneurysm rupture, suicide). 14 of the surviving 26 (54\%) remain on clozapine at most recent follow-up and demonstrated no significant change in the LVEF during this time $(p=0.66)$.

Those with LV impairment tended to be seen earlier than those who developed tachycardia without LV impairment (4.7 vs 7.2 years; $p=0.27)$. Patients in the former group were far more likely to have clozapine discontinued compared to those in the tachycardia group $(\mathrm{p}=0.03)$.

Discussion Clozapine use is associated with persistent tachycardia, myocarditis and cardiomyopathy; the latter carry significant morbidity and mortality. Despite being very effective, many will have clozapine stopped if there is evidence of

\begin{tabular}{|c|c|c|c|c|}
\hline & $\begin{array}{l}\text { Cardiomyopathy } \\
\text { group } \\
(n=11)\end{array}$ & $\begin{array}{l}\text { Tachycardia } \\
\text { group } \\
(n=18)\end{array}$ & $\begin{array}{l}\text { Total group } \\
(n=29)\end{array}$ & $p$ value \\
\hline Age, years (\%) & $41 \pm 15$ & $44 \pm 11$ & $43 \pm 12$ & 0.51 \\
\hline Gender (female) & $4(36 \%)$ & $5(28 \%)$ & $9(31 \%)$ & $\%$ \\
\hline $\begin{array}{l}\text { Length of time on } \\
\text { clozapine at review, } \\
\text { median (range) } \\
\text { years }\end{array}$ & $4.9(0.4-13)$ & $7.2(1.3-10)$ & $6.6(0.8-10)$ & 0.51 \\
\hline $\begin{array}{l}\text { Heart rate } \\
\text { Median (range) bpm }\end{array}$ & $83(76-90)$ & $103(97-115)$ & $98(85-114)$ & $0.0006^{*}$ \\
\hline $\begin{array}{l}\text { QRS duration } \\
\text { Median (range) ms }\end{array}$ & $90(88-98)$ & $90(85-95)$ & $90(86-95)$ & 0.66 \\
\hline $\begin{array}{l}\text { QTc interval } \\
\text { Median (range) ms }\end{array}$ & $431(416-440)$ & $441(418-468)$ & $\begin{array}{l}434(418- \\
458)\end{array}$ & 0.47 \\
\hline $\begin{array}{l}\text { LVEF } \\
\text { Median (range)\% }\end{array}$ & $45(37-50)$ & $55(52-55)$ & $52(44-55)$ & $<0.001^{*}$ \\
\hline $\begin{array}{l}\text { Clozapine } \\
\text { discontinued }\end{array}$ & $8(73 \%)$ & $5(28 \%)$ & $13(45 \%)$ & $0.027^{*}$ \\
\hline
\end{tabular}

cardiac toxicity. Our experience suggests that the shortmedium term outcome in these patients is acceptable with very low cardiac risk and no observable deterioration in LVEF.

Our findings support two distinct modes of cardiac toxicity. The underlying pathophysiology is not yet well defined and is likely to include patient-specific factors. Our data supports the feeling that tachycardia represents a benign process as all our patients had normal LVEF at the time of review.

Prospective studies are required in this complex group; the significance of QTc prolongation with clozapine use remains unclear and further study is warranted. We suggest that these patients should be managed in an interdisciplinary manner with close liaison between cardiologists and psychiatrists.

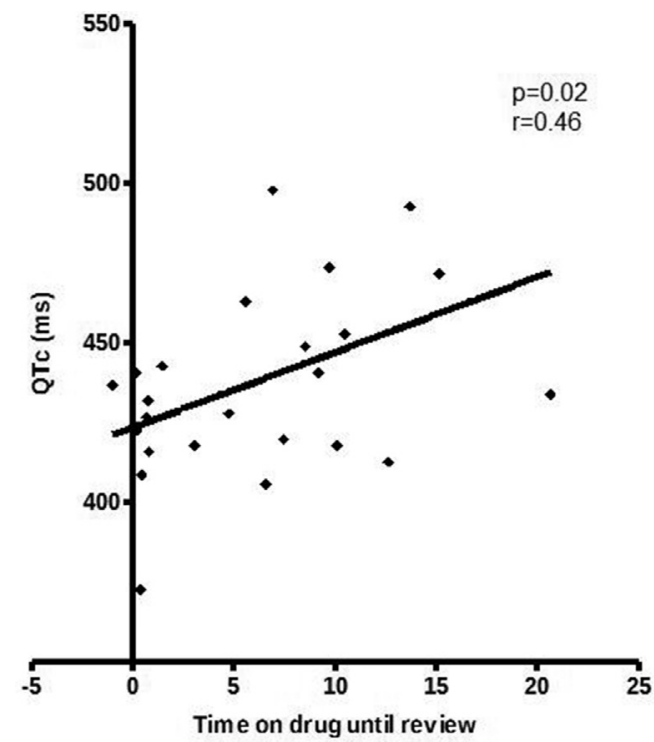

Abstract 12 Figure 1 QTc interval would appear to prolong in relation to time on Clozapine.

\section{KEEPING UP THE BEAT: A QUALITY IMPROVEMENT PROJECT ON HEART FAILURE MONITORING \& MANAGEMENT}

Mahvesh Rana Javaid*, Georgina Baca, Lovesh Dyall, Rumbi Maka, Jessica Dillaway, Margaret Chineah, William Young, Javed Akhtar. NHS

\subsection{6/heartinl-2017-311726.13}

Introduction There have been many cases observed in our cardiology wards and non-cardiology wards where heart failure patients are not having optimum fluid management and uptitrating therapy. One case led a patient to have prolonged hospital stay and outcome was death. Therefore, this project is important to raise awareness.

Currently, we only have a basic daily weight chart, which the nurses record the patients weight every morning. The heart failure medications are separately found on the drug chart, and bloods are found on Cyberlab. Plus the heart 


\section{Driver's Diagram:}

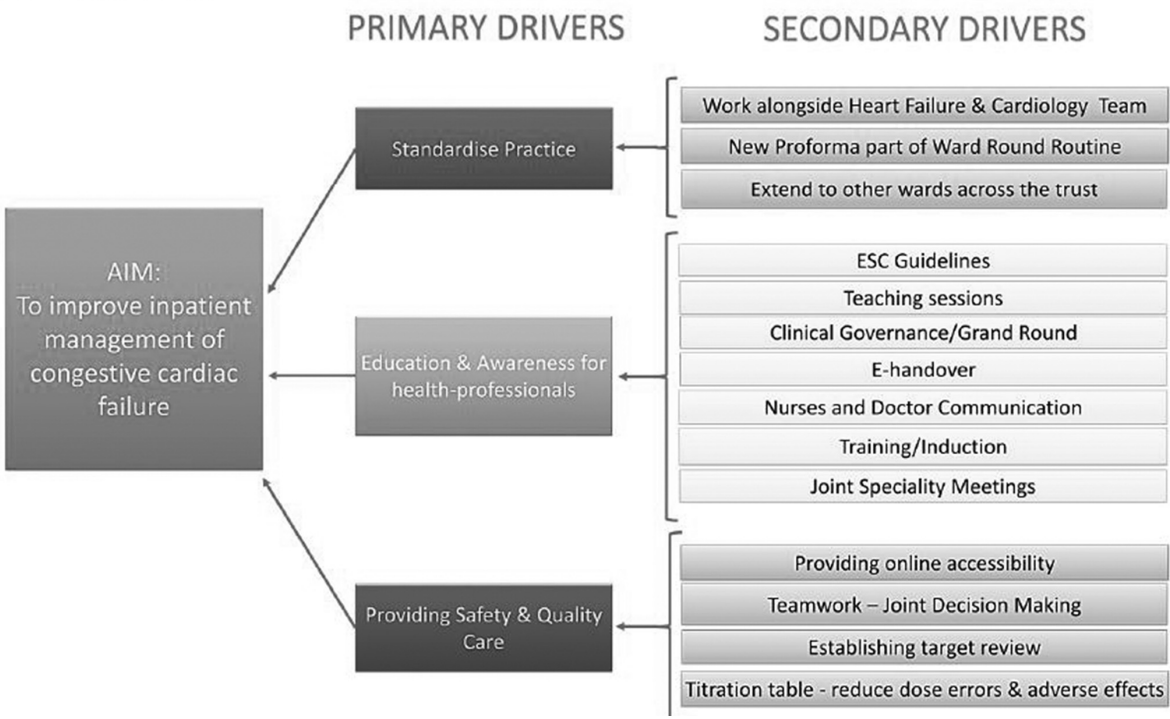

\section{Abstract 13 Figure 1}
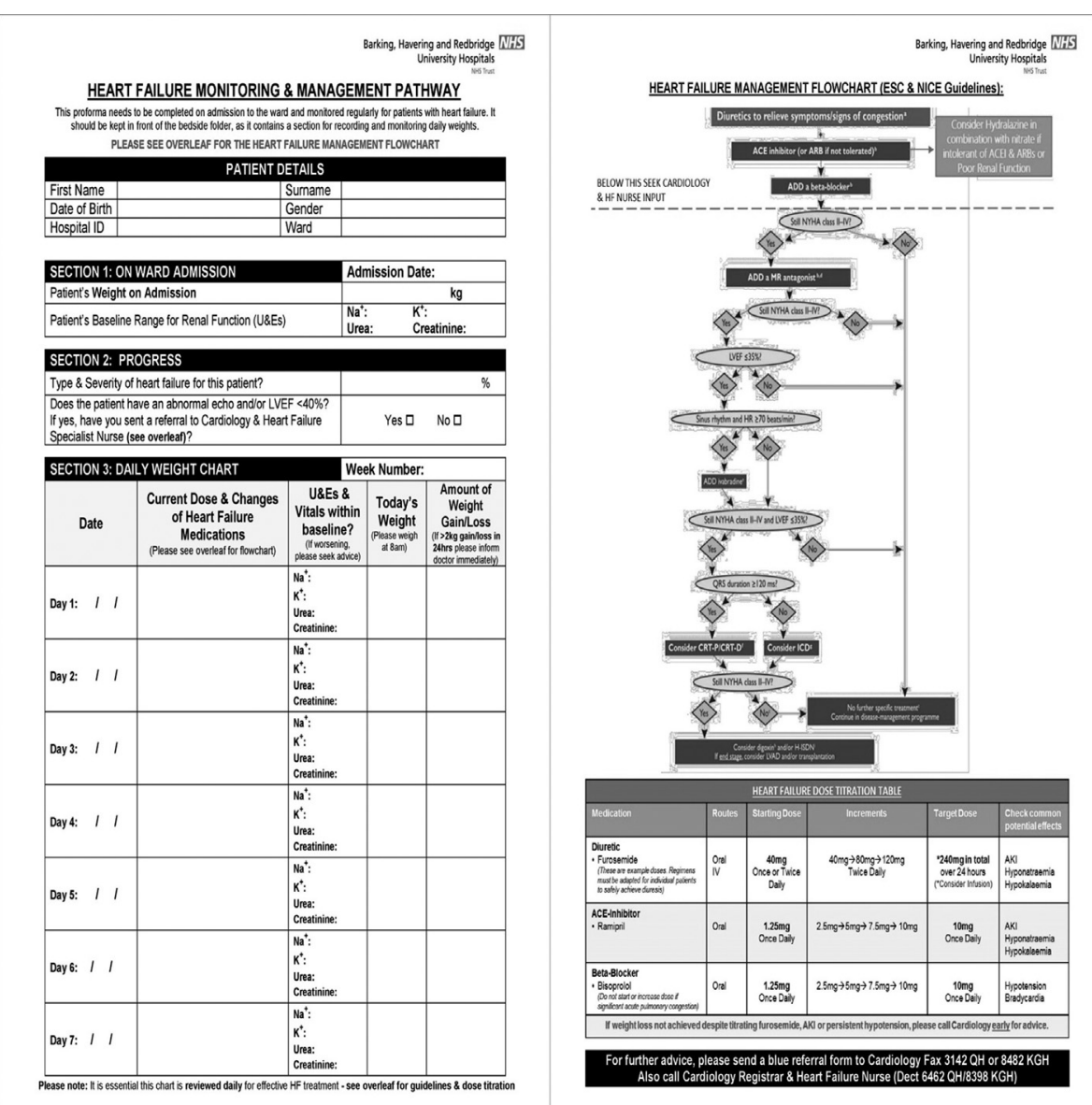

\section{Abstract 13 Figure 2}

failure guidelines are found on the European Society of Cardiology website. This shows that it takes a lot of effort and can cause time-consuming problems when accumulating this information together for heart failure monitoring; especially during busy ward round.

For effective heart failure monitoring, a new proforma was devised, which consists of daily weight, medications, $U$ and Es with electrolytes, patient heart failure details and admission weight. The guidelines (flow chart) are found at the back. This will be filled in by both nurses and doctors. This effectively improves titrating heart failure medications for better weight loss secondary to fluid overload. 
Aims and Outcomes To improve inpatient management of Congestive Cardiac Failure. By July 2016 at Queen's Hospital and King George Hospital, we should obtain 50\% in:

1. Optimising fluid management (weight loss)

2. Up-titrating therapy to maximum prognostic benefit

Methods 2 PDSA (Plan-Do-Study-Act) cycles were completed trust-wide project at BHR Hospitals "Queens" and $\mathrm{KGH}$ Coronary Care Units (Figure 1):

In PDSA Cycle 1, a two-week based proforma was trialled and compatibility was checked with daily ward round and CCF management. In PDSA Cycle 2, it was changed to a 7 days based proforma with an additional aspect on renal function (figure 2 see below). The new proforma was used, analysed and edited for each PDSA cycle. Patient parameters were derived and confirmed from Solus and Cyberlab.

Results There was a significant improvement from the new proforma in heart failure monitoring and management. The results are shown in table 1 :

\begin{tabular}{|c|c|c|}
\hline & PDSA Cycle 1 & PDSA Cycle 2 \\
\hline Number of Patients & $n=9$ & $n=10$ \\
\hline Mean Age & 73.9 & 70.2 \\
\hline Average Hospital Stay & 18.5 days & 17.5 days \\
\hline $\begin{array}{l}\text { Optimum Fluid } \\
\text { Management } \\
\text { (Percentage of Patient's } \\
\text { losing weight by Day } 7 \text { ) }\end{array}$ & $60 \%$ & $100 \%$ \\
\hline Developed Worsening AKI & $22 \%$ & $30 \%$ \\
\hline $\begin{array}{l}\text { Developed significant } \\
\text { electrolyte imbalance }\end{array}$ & $22 \%$ & $0 \%$ \\
\hline Up-titrating therapy & $22 \%$ & $100 \%$ \\
\hline $\begin{array}{l}\text { Quality of documentation: } \\
\text { Daily weights recorded }\end{array}$ & $89 \%$ & $100 \%$ \\
\hline $\begin{array}{l}\text { Quality of documentation: } \\
\text { U\&Es recorded }\end{array}$ & $55 \%$ & $100 \%$ \\
\hline
\end{tabular}

There were limitations with unwell patients, especially those who developed AKI secondary to heart failure treatment. With reducing hospital stay, helps reduce costs to the NHS.

Conclusions Heart Failure monitoring and management is important to help reduce morbidity and mortality. There was success from QI project by using the new proforma by improving patient care and co-ordinated care. It will be implemented in the trust on other medical wards like Acute Medicine.

\section{ST2 LEVELS ARE ELEVATED IN PATIENTS WITH ADVANCED HEART FAILURE BUT ARE NOT CONSISTENTLY ASSOCIATED WITH OTHER MARKERS OF ADVERSE PROGNOSIS}

${ }^{1}$ Hadyn Kankam, ${ }^{2}$ Nick Kirk, ${ }^{2}$ Sarah Fitzsimons, ${ }^{2}$ Stephen Pettit*. ${ }^{1}$ University of Cambridge; ${ }^{2}$ Papworth Hospital NHS Foundation Trust

\subsection{6/heartjnl-2017-311726.14}

Introduction Heart transplantation and mechanical circulatory support (MCS) improve survival in selected patients with advanced heart failure and an adverse prognosis. Soluble ST2 is a protein belonging to the interleukin-1 receptor family. ST2 is released in response to cardiomyocyte stess and thought to be a marker of adverse prognosis. We examined the association between ST2 levels and currently accepted markers of adverse prognosis in patients with advanced heart failure.

Methods We included 20 consecutive outpatients who were assessed for heart transplantation at Papworth Hospital over ten weeks. All patients underwent echocardiography, six minute walk testing, cardiopulmonary exercise testing and right heart catheterisation, in addition to blood tests including serum ST2 measurement using a commercial assay. Prognosis was estimated using the Seattle Heart Failure Model (SHFM) and the Meta-Analysis Global Group in Chronic Heart Failure (MAGGIC) scores. A multi-disciplinary team decided whether listing for heart transplantation was indicated. We examined the association between ST2 levels and other markers of adverse prognosis.

Results Ten patients were too well to be listed for heart transplantation (group A) and ten patients were sufficiently unwell to be listed for heart transplantation (group B). There was no difference in age, gender or body mass index. Key prognostic variables are presented in table 1 . Compared with patients in group A, patients in group B had higher ST2 levels, lower peak $\mathrm{VO}_{2}$, shorter six minute walk distance and higher SHFM

\begin{tabular}{|c|c|c|c|c|c|}
\hline & & Total & $\begin{array}{l}\text { Group A } \\
\text { (well, } n=10 \text { ) }\end{array}$ & $\begin{array}{l}\text { Group B } \\
\text { (unwell, } n=10 \text { ) }\end{array}$ & p value \\
\hline & LVEF (\%) & $17.5(12.5-52.5)$ & $17.5(13-35)$ & $20(12.5-52.5)$ & 0.1700 \\
\hline & Serum Creatinine (umol/L) & $120(53-653)$ & $110(53-175)$ & $140.5(89-653)$ & 0.6560 \\
\hline & NT-proBNP (pg/ml) & $2499(474-34491)$ & $2126.5(702-4594)$ & $5043.5(474-34491)$ & 0.6560 \\
\hline & $\mathrm{ST} 2(\mathrm{ng} / \mathrm{ml})$ & $54.17 \pm 42.91$ & $30.94 \pm 22.19$ & $77.19 \pm 46.86$ & $0.0110^{*}$ \\
\hline & Peak $\mathrm{VO}_{2}(\mathrm{ml} / \mathrm{kg} / \mathrm{min})$ & $15.1 \pm 4.7$ & $18.3 \pm 3.6$ & $11.8 \pm 3.1$ & $0.0004^{*}$ \\
\hline & $6 \mathrm{MWT}(\mathrm{m})$ & $346.1 \pm 103.1$ & $400.2 \pm 102.8$ & $292 \pm 73.2$ & $0.0143^{*}$ \\
\hline & Cardiac Index $\left(\mathrm{L} / \mathrm{min} / \mathrm{m}^{2}\right)$ & $1.97 \pm 0.37$ & $2.01 \pm 0.31$ & $1.94 \pm 0.44$ & 0.7053 \\
\hline & MAGGIC 1-year mortality (\%) & $14.42 \pm 5.73$ & $12.80 \pm 5.34$ & $16.04 \pm 5.91$ & 0.2130 \\
\hline & SHFM 1-year mortality (\%) & $8.30 \pm 5.28$ & $4.90 \pm 2.85$ & $11.70 \pm 5.01$ & $0.0015^{*}$ \\
\hline
\end{tabular}

